\title{
What are the top most costly diseases for USA? The alignment of burden of illness with prevention and screening expenditures
}

\author{
Guvenc Kockaya $^{1 *}$, Albert Wertheimer ${ }^{2}$ \\ ${ }^{1}$ Istanbul University, Istanbul Medical Faculty, Pharmacology and Clinical Pharmacology, Istanbul, Turkey; *Corresponding Author: \\ guvenckockaya@yahoo.com \\ ${ }^{2}$ Temple University, School of Pharmacy, Center for Pharmaceutical Health Services Research, Philadelphia, USA
}

Received 2 July 2010; revised 12 July 2010; accepted 20 July 2010.

\begin{abstract}
Background: It was the intention of the authors to generate a list of the top diseases responsible for the greatest financial expense in the United States. This listing would then inform polic-ymakers as to the highest priority target conditions. With such information available, funding for the NIH could be accomplished based upon factual criteria rather than political clout or uninformed consensus. Method: The first step was a literature review to explore articles and reports which were published about the cost of illness (COI) up to December 2009. Therefore the source of the data used in this investigation was obtained from this retrospective search approach. Results: With reference to total cost for disease, first was HCVD with $\mathbf{4 7 5 . 3}$ billion US dollars, followed by alcohol abuse and substance at $\mathbf{3 0 0 . 6}$ billion US dollars, digestive diseases at 259.6 billion US dollars, cancer at 239.5 billion US dollars and mental disease at 216,6 billion US dollars. Conclusion: As has been seen, the total societal costs of the diseases do not synch with the degree of attention paid to these various disease states. Several of the diseases have very powerful and vocal support organizations that encourage attention and clinical research support. On the other hand we hear very little about efforts against allergic rhinitis or infectious and parasitic diseases.
\end{abstract}

Keywords: Cost of Illness; Burden of Illness

\section{BACKGROUND AND INTRODUCTION}

It is difficult to avoid seeing examples of promotional ca- mpaigns encouraging women to self examine for potential breast cancer or advertisements for asthma, erectal dysfunction, GERD or hypertension medications. In fact during a typical day, many people are exposed to promotional messages regarding prevention, screening and/or treatment of a number of acute and chronic medical conditions. Logically speaking, it would seem rational to determine which diseases or medical conditions are the most costly to the society and then focus our attention on avoiding, treating or eliminating those medical conditions. But, in fact, as we know, the extent of advocacy against various problems is determined by a number of variables which may include the political connections of those involved, the fame or celebrity of a recent death from a condition or the recent diagnosis in a Hollywood star or famous athlete, or a whole host of other variables which may or may not have any serious connection to the priority of that particular disease state.

Apparently, upon the request of the US Senate, a study was undertaken which was published by the National Institutes of Health in the year 2000 where a large number of diseases were arrayed according to their total burden of cost upon the US society [1]. A study of this nature makes perfect sense since the Congress appropriates funds to support the various institutes of the NIH. Surely these legislators wanted to be certain that the disease states they were funding research and education for were the ones which should be tackled as a priority in the United States.

Also a study was published by Bloom [2] in the year 2001. They searched 1725 published study reports which included 80 different diseases from the year 1985 to 1999 and reported 17 different disease costs.

So it has been nearly 10 years since these studies were conducted and many of the flaws and shortcomings of the 2000 report may be corrected today given the far greater extent of available data and knowledge.

However, every year the NIH publishes direct and in- 
direct costs of 12 different main diseases categories [3]. There were not any published studies such as this one, which includes 19 main diseases with some subgroups resulting in a list of 32 different disease states. That makes this study unique.

\subsection{The Study}

It was the intention of the authors to generate a list of the top diseases responsible for the greatest financial expense in the United States. This listing would then inform policymakers as to the highest priority target conditions. With such information available, funding for the NIH could be accomplished based upon factual criteria rather than political clout or uninformed consensus.

\section{METHODOLOGY}

The first step was a literature review to explore articles and reports which were published about the cost of illness (COI) up to December 2009. Therefore the source of the data used in this investigation was obtained from this retrospective search approach. Also, it must be mentioned that there are a number of approaches for the calculation of the cost of illness. Some of these approaches are based on only direct costs and some are inclusive of only indirect costs. Clabaugh and Ward [4] reported that most COI studies included only one component.

The differences in data sources that influenced calculations were reported by them. We learned that the most frequently used data sources were from insurance or employer claims data and the second most commonly used approach involved publicly available data sets from the and NCHS or from the Agency for Healthcare Research and Quality. Considering that there are very many approaches, we defined the COI studies which would be employed. In our definition, COI studies, reviews or reports must include direct, indirect and total costs. We did not evaluate the data source used in preparing the COI numbers. Because of these limitations for the calculation of COI, incomplete numbers were used from various sources and matched together.

The first review included PubMed and the website for each diseases Society. Also used were the websites of the centers for disease control and prevention, and the National Institutes of Health support for selected diseases and conditions report. From these sources a listing of 55 different diseases was created. In the end we searched 8491 published documents. To be included it was determined that a study would have to adhere to the following criteria:

- a defined US national population

- report published in English in a peer reviewed journal

- conclusion of cost of illness data between 1999 and
December 2009

- inclusion of the direct, indirect and total costs of diseases

- inclusion of all diseases with costs higher than one billion US dollars

- inclusion of the latest data.

Included only those studies which were intended to shed light on the cost of illness question. Studies or reports which included economic outcome data such as cost-effectiveness or cost utility were ex-polluted. The studies which did not include all of the direct, indirect and total cost of diseases were also excluded and the NIH 2000 numbers were employed if no data subsequent to 1999 could be located.

In the end we listed 19 main diseases with some subgroups resulted in a list of 32 different disease states. All costs were adjusted to 2009 US dollars by using a yearly $5 \%$ inflation rate factor to adjust up to 2009 .

\section{RESULTS}

The list of cost of diseases may be seen in Table 1. We found that depression is the most articles and published journals about its cost of illness with 987 articles. Depression was followed by cancer (972), diabetes (747), mental disease (559) and schizophrenia (419), next was stroke with 410, asthma with 399, AIDS, 395, arthritis, 378 and tobacco/smoking related death and disease at 311 (Table 2).

Regarding only direct costs, the most costly disease was heart and cardiovascular disease (HCVD) with 313.8 billion US dollars, it was followed by digestive diseases at 220.8 billion US dollars, mental disease 175.7 billion US dollars; nervous system diseases 153.3 billion US dollars; diabetes 128,3 billion US dollars the complete list is seen in Table 3.

Similarly, the most costly indirect expenses these diseases was alcohol abuse and dependence 218.5 billion US dollars; HCVD at 161.4 billion US dollars; cancer 141.5 billion US dollars; tobacco/smoking related death and disease 101.85 billion US dollars and Alzheimer's disease 94 billion US dollars. The top five are seen in Table 4.

With reference to total cost for disease, first was $\mathrm{HC}$ VD with 475.3 billion US dollars, followed by alcohol abuse and substance at 300.6 billion US dollars, digestive diseases at 259.6 billion US dollars, cancer at 239.5 billion US dollars and mental disease at 216,6 billion US dollars the complete list is seen in Table 5.

\section{CONCLUSIONS}

As has been seen, the total societal costs of the diseases 
Table 1. Estimated cost of illness of the USA in 2009 from highest to lowest total cost.

\begin{tabular}{|c|c|c|c|c|}
\hline $\mathrm{N}$ & Disease & Direct Costs ${ }^{\mathrm{a}}$ & Indirect $\operatorname{Cost}^{\mathrm{a}}$ & Total Costs ${ }^{\mathrm{a}}$ \\
\hline \multirow[t]{4}{*}{1} & Heart \& CVD [5] & 313.8 & 161.4 & 475.3 \\
\hline & CHD [5] & 183 & 121.6 & 304.6 \\
\hline & Hypertension [5] & 54.2 & 19.2 & 73.4 \\
\hline & Stroke [5] & 45.9 & 23 & 68.9 \\
\hline 2 & Alcohol Abuse and Dependence [1] & 82 & 218.5 & 300.6 \\
\hline 3 & Digestive Disease [6] & 220.8 & 38.8 & 259.6 \\
\hline \multirow[t]{3}{*}{4} & Cancer [7] & 97.8 & 141.5 & 239.5 \\
\hline & Breast Cancer [1] & 10.7 & 10 & 20.8 \\
\hline & Cervical Cancer [7] & 5.5 & 0.6 & 6.1 \\
\hline \multirow[t]{3}{*}{5} & Mental Disease [6] & 175.7 & 40.9 & 216.6 \\
\hline & Depression [8] & 40.4 & 88.4 & 128.9 \\
\hline & Schzophrenia [9] & 31.9 & 45.5 & 88.2 \\
\hline 6 & Tobacco(smoking)-related Death and Disease [10] & 100.8 & 101.8 & 202.6 \\
\hline 7 & Diabetes [11] & 127.8 & 63.9 & 191.8 \\
\hline \multirow[t]{3}{*}{8} & Lung Diseases [6] & 113.6 & 63.8 & 177.4 \\
\hline & Chronic Obstructive Pulmonary Disease [12] & 27.8 & 33.1 & 49.5 \\
\hline & Asthma [12] & 14.6 & 5.8 & 20.5 \\
\hline \multirow[t]{4}{*}{9} & Diseases of the Nervous System [6] & 153.3 & 23.7 & 177 \\
\hline & Parkinson`s Disease [13] & 9.7 & 22.6 & 32.3 \\
\hline & Migraine [14] & 1.6 & 21.1 & 22.8 \\
\hline & Epilepsy [15] & 9.5 & 0.1 & 9.6 \\
\hline 10 & Rheumotoid Artritis [16] & 108.6 & 62.9 & 171.2 \\
\hline 11 & Alzheimer [3] & 54 & 94 & 148 \\
\hline 12 & Arthritis [1] & 24.7 & 80.7 & 105.5 \\
\hline 13 & Infectious and Parasitic Diseases [6] & 44 & 41.3 & 85.3 \\
\hline 14 & Over Active Bladder [17] & 22.3 & 33.5 & 55.8 \\
\hline 15 & Viral Respiratory Tract Infections (non influenza) [18] & 22.7 & 30.1 & 53.6 \\
\hline 16 & AIDS $[19]$ & 9.4 & 41.7 & 51.2 \\
\hline 17 & Influenza [20] & 11.4 & 17.9 & 40.4 \\
\hline 18 & Alergic Rhinitis [21] & 7.3 & 6.1 & 13.5 \\
\hline 19 & Sexual Transmitted Disease [22] & 9.1 & 0.9 & 10 \\
\hline
\end{tabular}

${ }^{\mathrm{a}}$ US Dollars in billions \& numbers are rounded

Table 2. The list of top 10 most cost-of illness published articles.

\begin{tabular}{|c|c|}
\hline Diseases & Article Numbers \\
\hline Depression & 987 \\
\hline Cancer & 972 \\
\hline Diabetes & 747 \\
\hline Mental Diseases & 559 \\
\hline Schizophrenia & 419 \\
\hline Stroke & 410 \\
\hline Asthma & 399 \\
\hline AIDS & 395 \\
\hline Arthritis & 378 \\
\hline Tobacco (Smoking)-Related Death and Disease & 311 \\
\hline
\end{tabular}


Table 3. The list of top 5 most direct costly diseases.

\begin{tabular}{lc}
\hline \multicolumn{1}{c}{ Diseases } & $\begin{array}{c}\text { Direct Costs (in billion US } \\
\text { dollars) }\end{array}$ \\
\hline Heart \& CVD & 313.8 \\
Digestive Diseases & 220.8 \\
Mental Diseases & 175.7 \\
Diseases of the Nervous System & 153.3 \\
Diabetes & 128.3 \\
\hline
\end{tabular}

Table 4. The list of top 5 most indirect costly diseases.

\begin{tabular}{lc}
\hline \multicolumn{1}{c}{ Diseases } & $\begin{array}{c}\text { Direct Costs } \\
\text { (in billion US dollars) }\end{array}$ \\
\hline Alcohol Abuse and Dependence & 218.5 \\
Heart \& CVD & 161.4 \\
Cancer & 141.5 \\
Tobacco(Smoking)-Related & 101.85 \\
Death and Disease & 94 \\
Alzheimer & 94 \\
\hline
\end{tabular}

Table 5. The list of top 5 most total cost diseases.

\begin{tabular}{lc}
\hline \multicolumn{1}{c}{ Diseases } & $\begin{array}{c}\text { Direct Costs } \\
\text { (in billion US dollars) }\end{array}$ \\
\hline Heart \& CVD & 475.3 \\
Alcohol Abuse and Dependence & 300.6 \\
Digestive Diseases & 259.6 \\
Cancer & 239.5 \\
Mental Diseases & 216.6 \\
\hline
\end{tabular}

do not synch with the degree of attention paid to these various disease states. Several of the diseases have very powerful and vocal support organizations that encourage attention and clinical research support.

On the other hand we hear very little about efforts against allergic rhinitis or infectious and parasitic diseases. In this study we learned that the most serious, fatal or terminal conditions are not always the ones most detrimental to the national economy. Probably more days are lost from work for diseases such as low back pain the common cold, seasonal flu, among others. Some of these so-called trivial or limited conditions may have serious economic consequences and therefore should not be automatically dismissed.

However, depression has the most articles found in our search, and its total cost is US\$128.9 billion. This cost gives it a place in the middle of the total cost list. Also it is the same as AIDS, which is in the lower end of the cost list, but it is on the top of the published article list.
Same explanation is in order for breast cancer and cervical cancer, as well. However much is said about taking action for breast or cervical cancer, yet direct, indirect and total costs for them are not as high for the society as chronic obstructive pulmonary disease (COPD) or as attention deficit hyperactivity disorder (ADHD) which were not even mentioned as much as breast cancer or cervical cancer.

On the other hand, alcohol abuse \& dependence and digestive diseases are in the top of the cost list. But, in society they are rarely spoken about as much as other diseases. Also they aren't in the top of the articles list. Because of its high costs, there is much publicity about prevention of digestive diseases and awareness projects about food safety or washing hands. For alcohol abuse \& dependence, there are projects about decreasing alcohol consumption like increasing the tax on alcohol or holding seminars in schools about alcohol abuse \& dependence, for creating public awareness.

Our study also shows that the best matched diseases are Heart \& CVD, Cancer and Mental Diseases. They are in the top of the cost list and in the top of article list. Also \frequently, we can see a project on television, in newspapers or journals for increasing public awareness.

Because if we can increase awareness of an illness, people may care about it and they may go to their physician regarding their signs and symptoms and be more compliant with their treatment. All of this may decreases the cost of illness to the reimbursement companies and to society.

By following our study findings, it could said that we need to care more about alcohol or tobacco dependence, digestive diseases such as heart and CVD, cancer or mental diseases.

\section{REFERENCES}

[1] Kirschtein, R. (2000) Disease-Specific Estimates of Direct and Indirect Costs of Illness and Department of Health and Human Services NIH Support, Washington DC. http://ospp.od.nih.gov/ecostudies/COIreportweb.htm

[2] Bloom, B.S., Bruno, D.J., Maman, D.Y. and Jayadevappa, R. (2001) Usefulness of US cost-of-1llness studies. Healthcare Decision Making Pharmacoeconomics, 19(2), 207-213.

[3] Alzheimer's Association (2009) Alzheimer's disease facts and figures. Alzheimers Dement, 5(3), 234-270.

[4] Clabaugh, G. and Ward, M.M. (2008) Cost-of-illness studies in the United States: A systematic review of methodologies used for direct cost value. Health, 11(1), 13-21.

[5] (2009) A Report from the American Heart Association Statistics Committee and stroke statistics subcommittee heart disease and stroke statistics. Update Circulation, 119, e21-e181.

[6] (2008) National Institutes of Health National Heart, Lung 
and Blood Institute Fact Book Fiscal Year, US Department of Health and Human Services, Washington, DC. www.nhlbi.nih.gov/about/factbook/FactBookFinal. pdf

[7] Lipsy, R.J. and Pharm, D. (2008) BCPS, FASHP assessing the short-term and long-term burden of 1llness in Cervical cancer. American Journal of Managed Care, 14, S177-S184.

[8] Greenberg, P.E. and Kessler, R.C. (2003) The economic burden of depression in the United States: How did it change between 1990 and 2000? Journal of Clinical Psychiatry, 64(12), 1465-1475.

[9] Wu, E.Q., Birnbaum, H.G., Shi, L., Ball, D.E., Kessler, R.C., Moulis, M. and Aggarwal, J. (2005) The economic burden of Schizophrenia in the United States in 2002, Journal of Clinical Psychiatry, 66(9), 1122-1129.

[10] Fiore, M.C., Jaén, C.R., Baker, T.B., et al. (2009) Treating tobacco use and dependence: 2008 date. quick reference guide for clinicians. Rockville, Department of Health and Human Services. Public Health Service. http://www.ahrq.gov/clinic/tobacco/tobaqrg.pdf

[11] (2008) American Diabetes Association Economic Costs of Diabetes in the U.S. in 2007. Diabetes Care, 31, 596-615.

[12] (2004) National heart, lung, and blood institute. Morbidity and mortality: 2004 chartbook on cardiovascular, lung, and blood diseases. US Department of Health and Human Services, Washington, DC.

[13] Huse, D.M., Schulman, K., Orsini, L., Castelli-Haley, J., Kennedy, S. and Lenhart, G. (2005) Burden of illness in Parkinson's disease. Movement Disorders, 20, 14491454.

[14] Henry, X. and Hu, M.D. (1999) Burden of Migraine in the United States. Archives of Internal Medicine, 159, 813-818.
[15] Yoon, D., Frick, K.D., Carr, D.A. and Austin, J.K. (2009) Economic impact of epilepsy in the United States. Epilepsia, 50(10), 2186-2191.

[16] Yelin, E., Murphy, L., Cisternas, M.G., Foreman, A.J., Pasta, D.J., Helmick, C.G. (2007) Medical care expenditures and earnings loses among persons with arthritis and other rheumatic condition in 2003. Arthritis and Rheumatism, 56(5), 1397-1407.

[17] Onukwugha, E. and Zuckerman, I.H. (2009) The total economic burden of overactive bladder in the United States: A disease-specific approach. American Journal of Managed Care, 15(4 Suppl.), S90-S97.

[18] Fendrick, A.M. and Monto, A.S. (2003) The economic burden of non-influenza-related viral respiratory tract infection in the United States. Arch Intern Med., 163(4), 487-494.

[19] Hutchinson, A.B., Farnham, P.G., Dean, H.D., Ekwueme, D.U., del Rio, C., Kamimoto, L., et al. (2006) The economic burden of HIV in the United States in the era of highly active antiretroviral therapy: Evidence of continuing racial and ethnic differences. Journal of Acquired Immune Deficiency Syndromes, 43(4), 451-457.

[20] Molinari, N.A. and Ortega-Sanchez, I.R. (2007) The annual impact of seasonal influenza in the US: Measuring disease burden and costs. Vaccine, 25(27), 5086-5096.

[21] Malone, D.C., Lawson, K.A., Smith, D.H., Arrighi, H.M., Battista, C. (1997) A cost of illness study of allergic rhinitis in the United States. Journal of Allergy and Clinical Immunology, 99(1 Pt 1), 22-27.

[22] Chesson, H.W., Blandford, J.M., Gift, T.L., Tao, G. and Irwin, K.L. (2004) The estimated direct medical cost of sexually transmitted diseases among American youth, 2000 perspectives on sexual and reproductive health. 36(1), 11-19. 